\title{
Thank you for 2010
}

\author{
Jón Karlsson · René Verdonk • Neil P. Thomas
}

Published online: 11 November 2010

(C) Springer-Verlag 2010

Now 2010 is coming to a close; it is the time to thank all of you for a great year. We would especially like to thank all the reviewers who devote their time and effort to improve the manuscripts submitted to the journal. We would also like to use this opportunity to impart some information about the current status of the journal.

The number of manuscripts has increased year on year, and 2010 is no exception. We have received approximately 750 manuscripts in 2010, compared with 685 in 2009 and 540 in 2008. These manuscripts are improving in quality, which is reflected in the quality of our journal. We are proud that we have published a great number of really good papers this year. This increase leads to a heavier workload for the Editors, Associate Editors and you the reviewers. Therefore, we would like to express our sincere gratitude to all of you who have reviewed manuscripts for KSSTA this year. This work is unpaid and time-consuming, but needs to be carefully performed.

Our ambition is to increase the contact with reviewers, for instance by sending you excellent reviews or other relevant information from time to time. Your feedback is also appreciated, so please do not hesitate to contact us at any time. We are happy that we have several new

\footnotetext{
J. Karlsson ( $\varangle)$

Department of Orthopaedics,

Sahlgrenska University Hospital, Gothenburg, Sweden

e-mail: jon.kssta@gmail.com

R. Verdonk

Department of Orthopaedics and Traumatology,

Ghent State University, Ghent, Belgium

N. P. Thomas

Winchester, UK
}

reviewers on our team. In order to facilitate your work, the journal has published new guidelines to reviewers which we are pleased to say are being heeded. At the ESSKA meeting in Oslo, the journal hosted a reviewers course in conjunction with the journal of Arthroscopy. The course was well attended, and we will host similar courses in the future.

The names of all reviewers are published below. Once more: thank you!

During the year we have worked on several changes, for example with the Instructions to Authors. We have added structured abstracts and from January 2011, all authors of clinical studies will be asked for level of evidence of their studies. We believe this will improve the journal.

As of January 2011, the new Editorial Board will be announced. Altogether 80 people were invited and have accepted an invitation to become members of the new Board. The people on the Editorial Board are extremely important as they will do the majority of the reviews, and this will hopefully guarantee the quality of our reviews. The journal is also working hard on speeding up the review process and reducing the time from submission to decision. With the new Editorial Board in place, the International Advisory Board will cease to exist. We would also like to use this opportunity to thank all those who served for Journal in the past both on the old Editorial Board and the International Advisory Board. When the new Board was considered, we searched for new people and are happy to include many young surgeons and researchers. We look forward working with you all in the future. The Board of Trustees has also been revitalised and will play an important role in the future development of the journal. We would like to use this opportunity to thank Giancarlo Puddu for his work on the Board of Trustees and welcome Alfredo Panni as new member. 
This year we have published more than 1,800 pages, compared with 1,450 pages in 2009 and 1,160 in 2008. This is a major increase and provides researchers a great opportunity to publish their work in the journal. Our submission base is truly international.

As you all will notice, from January 2011 the journal has a new front cover. The new cover is a strong sign that new winds are blowing. The journal also has a new webpage, and one important project for 2011 is to improve the website even more and to use it as a link to the ESSKA society and thus increase the communication with the readers.

The new Editorial Office in Luxembourg is now in place. This means that Louise von Essen, who has devoted her spare time (in addition to having a fulltime job), will be leaving the journal after 18 years of service. Louise has performed a great service for the journal; she has used her superb skills in a very effective manner. Speaking for the Editors and Associate Editors, we thank Louise for all the loyal and dedicated service you have given us through the years. An official thank was given to Louise at the ESSKA congress in Oslo. Now, effective of October 1st, the journal has an official Editorial Office for the first time where Elodie Reyter has taken over from Louise. They have worked in parallel for a few months in order to ensure a smooth transition. Elodie will devote the majority of her working hours to the journal; she will take care of all author correspondence, which means an increased and better author service and our immediate goal is to be able to speed up the administration of manuscripts and make the reviewing process smoother and quicker. So, do not hesitate to contact Elodie for all journal matters; her e-mail address is elodie.kssta@gmail.com. She will also administrate the Newsletter and will in such manner co-ordinate all ESSKA publishing. Concerning ESSKA publishing, we are currently discussing a Spin-off journal that might publish Case Reports and Technical Notes. The reason is that such papers are infrequently published in KSSTA.

We all know that the Impact Factor (IF) is the most important measure of journal ranking. The IF is based on the number of citations to papers published in the journal and other journals during the previous 2-year period. The current Impact Factor is 1.67 , which is almost the same as the previous year. The journal is currently rated as number 24 of 71 journals in the field of Sport Sciences. Our immediate goal is to increase the Impact Factor to at least 2.0 within the next year. We feel that this goal is realistic, but can only be achieved if KSSTA publishes the best possible manuscripts. High-quality papers will be read and cited by other researchers, and this leads to even better papers being submitted and published in the journal. This is the best way to boost the Impact Factor.

Overall, 2010 has been a good year for the journal. Several changes are being made and several more are coming soon. Together, all of us-Editors, Associate Editors, reviewers and writers-will co-operate to make KSSTA a leading journal in the field of sports sciences in the future. We are confident that 2011 will be an even better year.

We really look forward to working with all of you in the future.

Jón Karlsson, René Verdonk, Neil P. Thomas

Editors-in-Chief and Chair Board of Trustees

\section{0 reviewers}

Aagaard, Henrik, Denmark

Ackermann, Paul, Sweden

Adachi, Nobuo, Japan

Adravanti, Paolo, Italy

Agneskirchner, Jens, Germany

Alentorn-Geli, Eduard, Spain

Almqvist, Fredrik, Belgium

Amendola, Annunziato, USA

Amis, Andrew, UK

Anderson, Allen, USA

Andrish, Jack, USA

Arendt, Elizabeth, USA

Argenson, Jean-Noel, France

Arndt, Toni, Sweden

Arnold, Markus, Switzerland

Aroen, Asbjörn, Norway
Augustsson, Jesper, Sweden

Bak, Klaus, Denmark

Baldini, Andrea, Italy

Baranto, Adad, Sweden

Bartlett, John, Australia

Bauer, Thomas, France

Beaufils, Philippe, France

Becher, Christoph, Germany

Bellemans, Johan, Belgium

Bengtsson, Anders, Sweden

Blundell, Chris, UK

Bonnin, Michel, France

Bosch, Ulrich, Germany

Boström, Eva, Sweden

Brabant, Karl, Belgium

Briem, Kristin, Iceland
Brisby, Helena, Sweden

Bull, Anthony, UK

Cartucho, Antonio, Portugal

Castelli, Claudio, Italy

Catani, Fabio, Italy

Christel, Pascal, Saudi Arabia

Christiansen, Svend-Erik, Denmark

de Waal Malefijt, Maarten,

Netherlands

De Wilde, Lieven, Belgium

Defoort, Koen, Netherlands

Dejour, David, France

Dienst, Michael, Germany

Djian, Patrick, France

Donell, Simon, UK

Donley, Brian, USA 
Drogset, Jon-Olav, Norway

Einarsson, Fredrik, Sweden

Ejerhed, Lars-Erik, Sweden

Ekholm, Carl, Sweden

Ekstrand, Jan, Sweden

Eriksson, Karl, Sweden

Farr, Jack, USA

Fauno, Peter, Denmark

Felländer-Tsai, Li, Sweden

Feller, Julian, Australia

Ferretti, Andrea, Italy

Fonseca, Fernando, Portugal

Forriol, Francisco, Spain

Forssblad, Magnus, Sweden

Franz, Alois, Germany

Friederich, Niklaus, Switzerland

Frobell, Richard, Sweden

Fu, Freddie, USA

Fuchs-Winkelmann, Susanne, Germany

Fulkerson, John, USA

Gamelas, Joao, Portugal

Garofalo, Raffaele, Italy

Gerich, Torsten, Luxembourg

Giron, Francesco, Italy

Gliatis, Johnnone, Greece

Gobbi, Alberto, Italy

Good, Lars, Sweden

Granhed, Hans, Sweden

Grävare Silbernagel, Karin, USA

Hamidy, Vahid, Sweden

Handelberg, Frank, Belgium

Handl, Milan, Czech Republic

Hantes, Michael, Greece

Harilainen, Arsi, Finland

Heijne, Annette, Sweden

Hirschmann, Michael, Switzerland

Hofmann, Siegfried, Austria

Howell, Stephen, USA

Hulet, Christohp, France

Imhoff, Andreas, Germany

Jansson, Karl-Åke, Sweden

Jarvela, Timo, Finland

Järvinen, Teppo, Finland

Jenny, Jean-Yves, France

Jerosch, Joerg, Germany

Karahan, Mustafa, Turkey

Kartus, Jüri, Sweden

Kelberine, Francois, France

Kerkhoffs, Gino, Netherlands

Kessler, Oliver, Switzerland

Klos, Burt, Netherlands
Knobloch, Karsten, Germany

Knutsen, Gunnar, Norway

Kon, Elizaveta, Italy

Kondo, Eiji, Japan

Kopf, Sebastian, Germany

LaPrade, Robert, USA

Lemos, Alberto, Portugal

Leunig, Michael, Switzerland

Levy, Bruce, USA

Li, Guoan, USA

Lind, Martin, Denmark

Löken, Sverre, Norway

Lorbach, Olaf, Luxembourg

Lundberg, Mari, Sweden

Lundgreen, Kirsten, Norway

Lustig, Sebastien, France

Lysholm, Jack, Sweden

Macdonald, Peter, Canada

Madry, Henning, Germany

Maffulli, Nicola, UK

Marcacci, Maurillio, Italy

Martinez, Inigo, Norway

Marx, Robert, USA

Mayr, Hermann Otto, Germany

Meknas, Khaled, Norway

Menetrey, Jacques, Switzerland

Milano, Giuseppe, Italy

Moyen, Bernard, France

Muellner, Thomas, Austria

Muneta, Takeshi, Japan

Nakamura, Norimasa, Japan

Nebelung, Wolfgang, Germany

Newman, John, UK

Nilsson-Helander, Katarina, Sweden

Nordenson, Ulf, Sweden

Nordqvist, Anders, Sweden

Nyland, John, USA

Ochi, Mitsuo, Japan

O'Driscoll, Shawn, USA

Pape, Dietrich, Luxembourg

Pässler, Hans, Germany

Pearce, Christopher, UK

Pearle, Andrew, USA

Pederizini, Luigi Adriano, Italy

Peretti, Giuseppe, Italy

Perka, Carsten, Germany

Pfitzner, Tilman, Germany

Philippon, Marc, USA

Pillai, Anand, UK

Potel, Jean-Francois, France

Prodromos, Chadwick, USA
Pujol, Nicolas, France

Rahme, Hans, Sweden

Randelli, Filippo, Italy

Roemer, Frank, Germany

Roos, Harald, Sweden

Rühmann, Oliver, Germany

Salomonsson, Björn, Sweden

Salreta, José, Portugal

Saris, Daniel, Netherlands

Scheibel, Markus, Germany

Schiavone Panni, Alfredo, Italy

Schoettle, Philip, Germany

Sernert, Ninni, Sweden

Servien, Elvire, France

Shino, Konsei, Japan

Siebold, Rainer, Germany

Stark, André, Sweden

Stergiou, Nick, USA

Stukenborg-Colsman, Christina, Germany

Tashman, Scott, USA

Tegner, Yelverton, Sweden

Tengvar, Magnus, Sweden

Theisen, Daniel, Luxembourg

Thienpont, Emmanuel, Belgium

Thijs, Youri, Belgium

Thomas, Neil, UK

Thomee, Roland, Sweden

Valentin, Anders, Sweden

Van den Daelen, Luc, Belgium

van Eck, Carola, USA

Van Giffen, Nicolien, Luxembourg

van Hellemondt, Gijs, Netherlands

Van Loon, Corné, Netherlands

Vandekerckhove, Bruno, Belgium

Vandenneucker, Hilde, Belgium

Verdonk, Peter, Belgium

Verdonschot, Nico, Netherlands

Victor, Jan, Belgium

Volpi, Piero, Italy

von Knoch, Fabian, Switzerland

Warner, Jon JP, USA

Weidenhielm, Lars, Sweden

Wickiewicz, Thomas, USA

Willems, Jaap, Netherlands

Wilton, Timothy, UK

Witvrouw, Erik, Belgium

Wymenga, Ate, Netherlands

Yasuda, Kazunori, Japan

Zaffagnini, Stefano, Italy

Zantop, Thore, Germany

Zeisig, Eva, Sweden 